1996

\title{
Hydrogenation Of Undoped And Nitrogen-Doped Cdte Grown By Molecular Beam Epitaxy
}

Zhonghai Yu

S. L. Buczkowski

M. C. Petcu

N. C. Giles

T. H. Myers

Follow this and additional works at: https://researchrepository.wvu.edu/faculty_publications

\section{Digital Commons Citation}

Yu, Zhonghai; Buczkowski, S. L.; Petcu, M. C.; Giles, N. C.; and Myers, T. H., "Hydrogenation Of Undoped And Nitrogen-Doped Cdte Grown By Molecular Beam Epitaxy" (1996). Faculty Scholarship. 556.

https://researchrepository.wvu.edu/faculty_publications/556 


\section{Hydrogenation of undoped and nitrogen-doped CdTe grown by molecular beam epitaxy}

Zhonghai Yu, S. L. Buczkowski, M. C. Petcu, N. C. Giles, and T. H. Myers ${ }^{\text {a) }}$

Department of Physics, West Virginia University, Morgantown, West Virginia 26506-6315

(Received 12 October 1995; accepted for publication 14 November 1995)

The effect of atomic hydrogen during the growth of undoped and nitrogen-doped CdTe by photon-assisted molecular beam epitaxy was investigated. Hydrogen incorporation is enhanced by the presence of nitrogen. Infrared absorption measurements strongly suggest the formation of $\mathrm{N}-\mathrm{H}$ complexes. Hall measurements indicate that the complexes are donorlike in nature. Hydrogenation radically changes the low temperature photoluminescence in both undoped and nitrogen-doped layers. Exciton-related luminescence is quenched at low temperature. Nitrogen-related donor-acceptor pair luminescence is also absent from $\mathrm{N}$-doped hydrogenated layers, consistent with complex formation. Copper donor-acceptor pair luminescence appears to be enhanced by hydrogen.

(C) 1996 American Institute of Physics. [S0003-6951(96)04604-X]

The ubiquitous nature of hydrogen during the growth and processing of semiconductors requires an understanding of its effects on dopant compensation and point defect formation. ${ }^{1}$ For example, residual hydrogen in a molecular beam epitaxy (MBE) system can cause significant dopant compensation for materials such as $\mathrm{Mg}$ in $\mathrm{GaN} .^{2}$ Effects due to hydrogen are significantly larger for metalorganic chemical vapor deposition (MOCVD) and metalorganic MBE growth (MOMBE). ${ }^{3-5}$

Reports on hydrogenation of II-VI semiconductors remain scarce. Studies of bulk CdZnTe exposed to a hydrogen plasma indicated quenching of donor-acceptor pair (DAP) and electron-acceptor $(\mathrm{e}, A)$ photoluminescence assigned to Cd vacancies. ${ }^{6,7}$ Similar quenching was observed for $\mathrm{ZnSe}^{8}$ for an unspecified donor and acceptor. Annealing of nitrogen-implanted CdTe in hydrogen reduced DAP luminescence attributed to nitrogen. ${ }^{9}$ Absorption studies using a Fourier transform infrared spectrometer (FTIR) indicate the formation of complexes between $\mathrm{H}$ and $\mathrm{As}$ in CdTe and $\mathrm{ZnTe}$, between $\mathrm{H}$ and $\mathrm{P}$ in $\mathrm{ZnTe}$ grown by MOCVD, ${ }^{10}$ and between $\mathrm{H}$ and $\mathrm{N}$ in $\mathrm{ZnSe}$ grown by MOCVD and MOMBE. ${ }^{3-5}$ In this letter, we report on the use of a thermal atomic hydrogen source to investigate hydrogenation of undoped and nitrogen-doped CdTe grown by MBE. .

The CdTe layers were grown at West Virginia University using photon-assisted MBE in a system similar to that described elsewhere. ${ }^{11} \mathrm{CdTe}$ films were grown on (100) and (211)B substrates using a single source of $\mathrm{CdTe}$, all provided by II-VI, Inc. (Saxonburg, PA). The $2 \mu \mathrm{m}$ thick layers were grown at $230^{\circ} \mathrm{C}$ at a rate of $0.3 \mu \mathrm{m} / \mathrm{h}$ under an illumination intensity of $75 \mathrm{~mW} / \mathrm{cm}^{2}$ (514.5 $\mathrm{nm}$ line, argon ion laser). Doped layers were grown with an undoped $0.3 \mu \mathrm{m}$ buffer layer. A cryogenically cooled if plasma source (Oxford Applied Research CARS-25) was used for nitrogen doping. Atomic hydrogen was produced using a thermal cracker (EPI).

$\mathrm{X}$-ray diffraction rocking curve measurements indicated

${ }^{a j}$ Electronic mail: thmyers@wvnvms.wvnet.edu no measurable difference in crystal quality between epilayers grown with or without hydrogen and the original substrates. Undoped layers were $p$-type with carrier concentrations of about $5 \times 10^{16} \mathrm{~cm}^{-3}$ as determined by Hall measurements. Secondary ion mass spectrometry (SIMS) performed at Charles Evans and Associates (Redwood City, CA) indicated $\mathrm{Cu}$ at this level, apparently diffusing from the substrate. No other impurities were detectable by SIMS above instrumental background in these layers.

Low-temperature PL measurements were performed using the $514.5 \mathrm{~nm}$ argon ion laser line at a power density of $3.1 \mathrm{~W} / \mathrm{cm}^{2}$. All spectra shown are corrected for system response. A 4.8 K PL spectrum typical of the undoped layers is shown in Fig. 1(a). The dominant emission line at $1.5894 \mathrm{eV}$ is due to the copper-acceptor $\left(\mathrm{Cu}_{\mathrm{Cd}}\right)$ bound-exciton recombination ${ }^{12}$ with an $\mathrm{LO}$-phonon replica at $1.568 \mathrm{eV}$. The absence of significant emission at lower energies, particularly DAP emission, indicates an absence of donor impurities in the undoped layers.

Nitrogen doping was accomplished using a 3 $\times 10^{-6}$ Torr beam equivalent pressure (BEP) from the if plasma source operating at $275 \mathrm{~W}$. By varying growth conditions, $\mathrm{N}$ concentrations were obtained that ranged from 5 $\times 10^{16}$ to $2 \times 10^{17} \mathrm{~cm}^{-3}$ with an instrumental background of about $3 \times 10^{16} \mathrm{~cm}^{-3}$. Hall measurements indicated $p$-type layers with a high degree of dopant activation. However, interpretation was complicated by a large nitrogen accumulation at the doped layer/buffer layer interface in many of the layers. $^{13}$

A PL spectrum typical of the CdTe: $\mathrm{N}$ layers is shown in Fig. 1(b). The dominant recombination at $1.5898 \mathrm{eV}$ is attributed to nitrogen-acceptor $\left(\mathrm{N}_{\mathrm{Te}}\right)$ bound-exciton recombination. ${ }^{14}$ The LO-phonon replica of the boundexciton line appears at $1.568 \mathrm{eV}$. The $\left(\mathrm{e}, A^{0}\right)$ and the DAP emission related to $\mathrm{N}_{\mathrm{Te}}$ occur at 1.550 and $1.543 \mathrm{eV}$, respectively, with several orders of phonon replicas. ${ }^{9.14-16}$ Note that the DAP band indicates the presence of a shallowionization-energy donor in the layers. Two-electrontransition spectroscopy indicates the donor is a halogen impurity, most likely fluorine, and not a defect complex as 


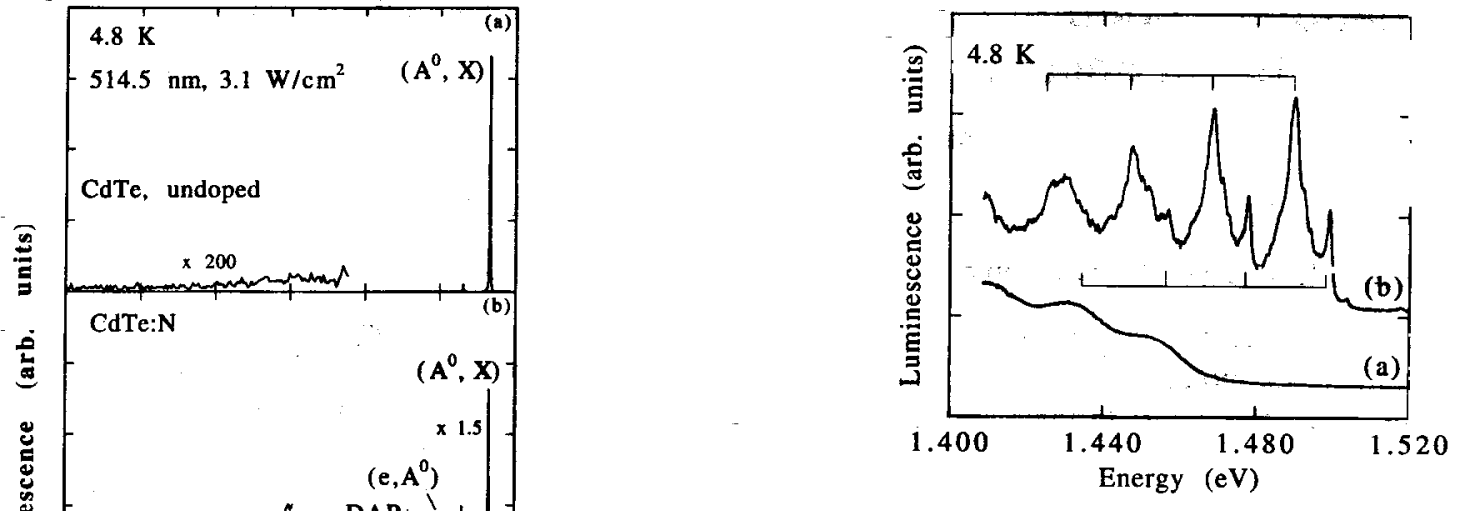

FIG. 2. Selective excitation photoluminescence of CdTe:N,H with (a) above band-gap excitation and (b) excitation tuned below the shallow donor energy level. The curves are displaced for comparison.

gap of $1.606 \mathrm{eV}$, we observed a distinct set of PL lines occurring only in films grown in the presence of hydrogen. The curve shown in Fig. 2(b) was obtained using excitation at $1.5867 \mathrm{eV}(7811.9 \AA)$ which is below the shallow donor level in CdTe. The DAP band is gone as expected. However, two series of sharp lines with zero-phonon peaks at 1.4991 and $1.4899 \mathrm{eV}$ appear, along with several orders of phonon replicas occurring at $2 \mathfrak{l} \mathrm{meV}$ intervals (indicated by the lines). The two series of lines show distinctly different temperature behavior. The $1.4899 \mathrm{eV}$ lines decrease with increasing temperature, while the 1.4991 emission increases up to a temperature of $45 \mathrm{~K}$, whereby it then decreases. In addition, the $1.4991 \mathrm{eV}$ emission is extremely sensitive to excitation energy and is best seen when the Ti:sapphire laser was tuned to about $1.587 \mathrm{eV}$. In contrast, the recombination mechanisms resulting in the $1.4899 \mathrm{eV}$ transition have a very broad absorption band ranging from 1.50 to $1.59 \mathrm{eV}$.

The origins of the new PL lines shown in Fig. 2(b) are not yet completely understood although the emission appears to be related to the presence of hydrogen during growth. In the previous report of hydrogen interactions with nitrogen acceptors in CdTe, ${ }^{9}$ no new PL features were observed. The excitation energy and temperature behavior of the $1.4899 \mathrm{eV}$ transition is similar to that attributed to isoelectronic oxygen centers in $\mathrm{ZnTe} .{ }^{18}$ However, the emission energies do not correspond to that associated with isoelectronic oxygen in CdTe. ${ }^{19}$ We are currently performing a more detailed study of this interesting transition.

A SIMS depth profile for hydrogen and nitrogen was obtained from a CdTe:N,H sample consisting of $1 \mu \mathrm{m} \mathrm{CdTe}$ grown under both a nitrogen and hydrogen flux on top of 1 $\mu \mathrm{m}$ of CdTe grown only under a hydrogen flux. A distinct step was observed in the hydrogen signal that correlated with the increase in nitrogen concentration from background to about $1 \times 10^{17} \mathrm{~cm}^{-3}$ in the top layer. Within the accuracy of the measurement, the increase in hydrogen concentration matched or exceeded that of nitrogen indicating nitrogenenhanced hydrogen incorporation similar to that reported for $\mathrm{ZnSe}: \mathrm{N}, \mathrm{H} .{ }^{5}$ Hall measurements indicated that the CdTe:N,H samples were heavily $n$ type, with carrier concentrations of about $1 \times 10^{17} \mathrm{~cm}^{-3}$.

Absorption spectra were taken using a Nicolet model 


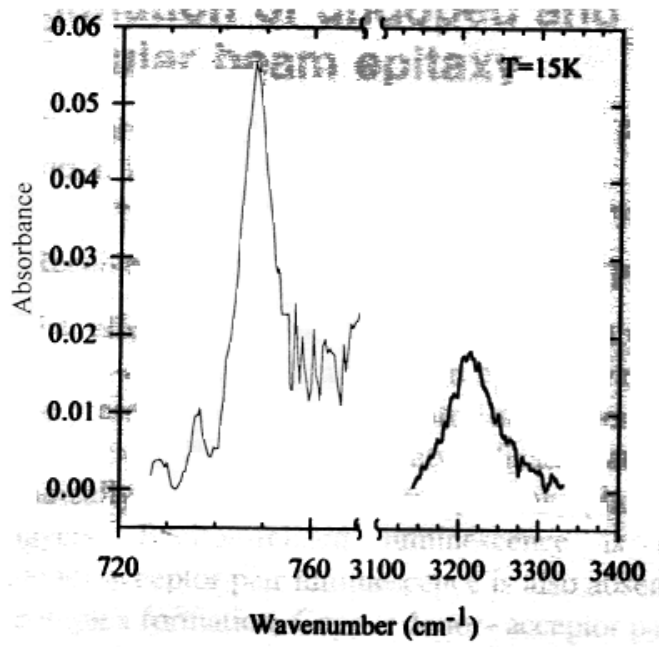

FIG. 3. Fourier transform infrared spectroscopy measurement showing absorption features related to nitrogen-hydrogen complex formation in CdTe:N,H.

550 FTIR spectrometer at $15 \mathrm{~K}$. Two new absorption features, shown in Fig. 3, were observed at about 3210 and 749 $\mathrm{cm}^{-1}$ for the CdTe:N,H samples. These features, absent for undoped layers, nitrogen-doped layers grown without a hydrogen flux, undoped layers grown under a hydrogen flux, and bare substrates, are taken as an indication of $\mathrm{N}-\mathrm{H}$ bonding. The $3210 \mathrm{~cm}^{-1}$ peak can be associated with the $\mathrm{N}-\mathrm{H}$ stretching mode, similar to the $\mathrm{N}-\mathrm{H}$ stretching mode absorption at $3193-3194 \mathrm{~cm}^{-1}$ in $\mathrm{ZnSe},{ }^{3,4}$ the $3336 \mathrm{~cm}^{-1}$ stretching mode in ammonia molecules, ${ }^{20}$ and the $3340 \mathrm{~cm}^{-1}$ absorption band observed for $a-\mathrm{SiN}: \mathrm{H}^{2 \mathrm{I}}$

Wolk et al. ${ }^{3}$ observed an FTIR peak in $\mathrm{ZnSe}: \mathrm{N}, \mathrm{H}$ at 783 $\mathrm{cm}^{-1}$. Using polarized Raman spectroscopy measurements, they verified that this feature was only observed for the scattering geometries consistent with a $\mathrm{N}-\mathrm{H}$ wagging mode. Following their reasoning, we assign the feature at $749 \mathrm{~cm}^{-1}$ to the $\mathrm{N}-\mathrm{H}$ wagging mode in CdTe. The presence of both features only in the sample with significant nitrogen and hydrogen strongly implies that $\mathrm{H}$ forms a complex with $\mathrm{N}$ acceptors in CdTe. Thus, it is easy to understand the quenching of PL associated with nitrogen due to complex formation. The presence of the $\mathrm{N}-\mathrm{H}$ bond removes the $\mathrm{N}$ from acting as an acceptor. Indeed, the $\mathrm{N}-\mathrm{H}$ complex appears donôrlike based on the Hall results.

These data, coupled with previous reports of $\mathrm{N}-\mathrm{H}$ bonding in $\mathrm{ZnSe},{ }^{3-5} \mathrm{As}-\mathrm{H}$ bonding in $\mathrm{CdTe}$ and $\mathrm{ZnTe},{ }^{10}$ and $\mathrm{P}-\mathrm{H}$ bonding in $\mathrm{ZnTe},{ }^{10}$ indicate a trend that $\mathrm{H}$ will form a strong bond to group V dopant atoms. Thus, care must be taken to minimize hydrogen compensation not only in the growth but also in subsequent processing steps. The presence of $\mathrm{Cu}$ related DAP PL implies that $\mathrm{H}$ either does not form complexes with $\mathrm{Cu}$, or the complexes are unstable at the growth temperature. A speculation is that $p$-type dopants on the metal sublattice may not form compensating bonds with hydrogen.

In summary, hydrogenation during the growth of undoped and nitrogen-doped CdTe has been investigated. Quenching of exciton-related PL was observed, while $\mathrm{Cu}$ related DAP luminescence was enhanced. New PL features were measured that appear to be related to hydrogenation. Results of PL, SIMS, and FTIR measurements made on CdTe:N,H samples are consistent with $\mathrm{N}-\mathrm{H}$ complex formation.

We thank II-VI, Inc. for substrate and source material, and Lauren Hirsch for operating the FTIR. This work was supported by the West Virginia/National Science Foundation EPSCoR program and two NSF Instrumentation Grants Nos. DMR92-08130 and DMR92-14350.

'See, for example, Semiconductors and Semimetals: Hydrogen in Semiconductors, edited by J. I. Pankove and N. M. Johnson (Academic, San Diego, 1991), Vol. 34.

${ }^{2}$ M. S. Brandt, J. W. Ager III, W. Gotz, N. M. Johnson, J. S. Harris, R. J. Molnar, and T. D. Moustakas, Phys. Rev. B 49, 14758 (1994).

${ }^{3}$ J. A. Wolk, J. W. Ager III. K. J. Duxtad, E. E. Haller, N. R. Taskar, D. R. Dorman, and D. J. Olego, Appl. Phys. Lett. 63, 2756 (1993).

${ }^{4}$ A. Kamata, H. Mitsuhashi, and H. Fujita, Appl. Phys. Lett. 63, 3353 (1993).

${ }^{5}$ E. Ho, P. A. Fisher, J. L. House, G. S. Petrich, L. A. Kolodziejski, J. Walker, and N. M. Johnson, Appl. Phys. Lett. 66, 1062 (1995).

${ }^{6}$ M. D. Kim, T. W. Kang, J. M. Kim, H. K. Kim, Y. T. Jeoung, and T. W. Kim, J. Appl. Phys. 73, 4077 (1993).

${ }^{7}$ Y. F. Chen. C. S. Tsai, Y. H. Chang. Y. M. Chang T. K. Chen , and Y. M. Pang, Appl. Phys. Lett. 58, 493 (1991).

${ }^{8}$ C. Pong, N. M. Johnson, R. A. Street, J. Walker, R. S. Feigelson, and R. C. DeMattei, Appl. Phys. Lett. 61, 3026 (1992).

${ }^{9}$ A. Boudoukha, R. Legros, L. Svob, and Y. Marfaing, J. Cryst. Growth 72, 226 (1985).

${ }^{10}$ L. Svob, Y. Marfaing, B. Clerjaud, D. Cote, D. Ballutaud, B. Theys, R. Druilhe, W. Kuhn, H. Stanzl, and W. Gebhardt, Mater. Sci. Forum 137147, 447 (1994).

"T. H. Myers, R. W. Yanka, K. A. Harris, A. R. Reisinger, J. Han, S. Hwang, Z. Yang, N. C. Giles, J. W. Cook, Jr., J. F. Schetzina, R. W. Green, and S. McDevitt, J. Vac. Sci. Technol. A 7, 300 (1989).

${ }^{12}$ E. Molva, J. L. Pautrat, K. Saminadayar, G. Milcherg, and N. Magnea, Phys. Rev. B 30, 3344 (1984).

${ }^{13}$ Zhonghai Yu, S. L. Buczkowski, M. C. Petcu, N. C. Giles, T. H. Myers, and M. R. Richards-Babb, J. Electron. Mater. (to be published).

${ }^{14}$ K. A. Dhese, P. Devine, D. E. Ashenford, J. E. Nicholls, C. G. Scott, D. Sands, and B. Lunn, J. Appl. Phys. 76, 5423 (1994).

${ }^{15}$ H. Pauli, K. Hingerl, E. Abramof, H. Sitter, H. Zajicek, and K. Lischka, J. Appl. Phys. 73, 4061 (1993).

${ }^{16}$ T. Baron, S. Tatarenko, K. Saminadayar, N. Magnea, and J. Fontenille, A p̂pl. Phys. Lett. 65, 1284 (1994).

${ }^{17}$ T. H. Myers, K. A. Harris, R. W. Yanka, L. M. Mohnkern, R. J. Williams, and G. K. Dudoff, J. Vac. Sci. Technol. B 10, 1438 (1992).

${ }^{18}$ J. L. Merz, Phys. Rev. 176, 961 (1968).

${ }^{19}$ K. Akimoto, H. Okuyama, M. Ikeda, and Y. Mori, Appl. Phys. Lett. 60, 91 (1992).

${ }^{20} \mathrm{G}$. Herzberg, Molecular Spectra and Molecular Structure II: Infrared and Raman Spectra of Polyalomic Molecules (Van Nostrand, New York, 1966), p. 295.

${ }^{21}$ H. Kurata, M. Hirose, and Y. Osaka, Jpn. J. Appl. Phys. 20, L8I1 (1981). 